\title{
Herrera, Carlos (2019). En vísperas del diluvio. El gremialismo socialista ante la irrupción del peronismo. Mar del Plata: Eudem- Grupo Editor Universitario
}

\section{Federico Martocci}

fedmartocci@hotmail.com

Consejo Nacional de Investigaciones Científicas y

Técnicas, Instituto de Estudios Históricos y Sociales

de La Pampa (CONICET-UNLPam)/Instituto

de Estudios Socio-Históricos, Facultad de Ciencias

Humanas (UNLPam), Argentina

Cita sugerida: Martocci, F. (2021). [Revisión del libro En vísperas del diluvio. El gremialismo socialista ante la irrupción del peronismo por C. Herrera]. Anuario del Instituto de Historia Argentina, 21(2), e156.

https://doi.org/10.24215/2314257Xe156

Este libro de Carlos Miguel Herrera, un referente de los estudios sobre el socialismo en la Argentina, constituye una sólida contribución en un área temática que en las últimas décadas experimentó una renovación notable. Por cierto, la obra que coordinó en 2005 junto con Hernán Camarero, titulada El Partido Socialista en Argentina: sociedad, politica e ideas a través de un siglo, y su otro trabajo publicado en 2016 que lleva por título ¿Adiós al proletariado? El Partido Socialista bajo el peronismo (1945-1955), dan cuenta de un autor activo en la producción de conocimientos vinculados con la historia del Partido Socialista (PS), en particular con el devenir de esa fuerza política entre las décadas de 1930 y 1950. En vísperas del diluvio se puede leer en esa clave de producción historiográfica, y resulta un excelente mirador para comprender, a partir de una lectura ágil (aunque no menos erudita) y atractiva, el papel del socialismo en el movimiento obrero 
en el curso de los años treinta y durante los albores del peronismo. Por cierto, este nuevo estudio, incluido en una valiosa colección que interpela a un público lector amplio (y no solo académico), puede abordarse como un complemento de su obra de 2016 y logra conjugar aportes previos y planteos novedosos.

En un movimiento que ya este autor validó en términos analíticos, propone aquí partir de la década de 1930 y revisar un aspecto esencial para comprender el gremialismo socialista: la denominada "política de prescindencia", teorizada por Juan B. Justo y codificada hacia 1918, pero que luego tuvo varias "traducciones". Es por ello que el primer capítulo se abre con una revisión de ese tema. Si bien la prescindencia ya había dado lugar a calurosos debates y conflictos en el PS, con el golpe de Estado que derrocó a Hipólito Yrigoyen la revisión de esta doctrina se convirtió en una cuestión apremiante a raíz de las dificultades que acarreaba para el proyecto socialista. En dicha coyuntura, la prescindencia se aggiorno en un marco en el que también aparecieron tensiones en el PS con la dirigencia sindical, las cuales no se ceñían al enfrentamiento entre derecha e izquierda partidaria y tenían su acicate en la promoción de líneas políticas propias desde las organizaciones sindicales. Ello ocurrió en un contexto particular: los gremialistas socialistas habían desplazado a la conducción sindicalista de la CGT y se había acrecentado el número de diputados nacionales del PS que tenían una procedencia obrera. Uno de los que encarnaba esa vertiente política autónoma era Francisco Pérez Leirós, un referente de los trabajadores municipales y un destacado dirigente político.

Si el libro se inicia con una apropiada caracterización de dicho marco, que llevó a Alfredo López (un autor clave en la prensa partidaria sobre temas sindicales) a señalar que la prescindencia constituía un "mito" hacia mediados de los años treinta, el segundo capítulo se detiene en la "crisis interna" que atravesaron los gremialistas del PS. En tal sentido, identifica una tensión clara entre dos líneas: por un lado, la que encabezaba José Domenech, que era el referente de la Unión Ferroviaria (UF), y por otro la que representaba Pérez Leirós, el secretario general de la Unión Obreros Municipales. Allí se exploran los perfiles de ambos dirigentes, elección muy atinada para mostrar la relación de estos con el PS: más "laxa” en el caso de Domenech, así como también en el de su mano derecha Camilo Almarza; y mucho más orgánica y de larga data en el caso de Pérez Leirós, quien se había afiliado al PS ya en 1912. Estas líneas se acercaron entre 1940-1941, con el objetivo de aislar a los comunistas en el seno de la CGT, pero a partir de 1942 nuevamente se distanciaron y el sector de Pérez Leirós y Ángel Borlenghi (que tenía inveterados vínculos con el PS) mostró posiciones más cercanas con los comunistas, e incluso compartieron tribuna con referentes obreros de esa fuerza política. En ese contexto se explica el conflicto en el interior de la CGT, con durísimas críticas de la dirección de la central obrera a las maniobras de la Federación Obrera Nacional de la Construcción (FONC), donde el Partido Comunista tenía un peso sustancial. Si el II Congreso Ordinario de la CGT (realizado en diciembre de 1942) mostró las fisuras de la central, los meses siguientes dieron lugar a su división, proceso que dejó en veredas opuestas a Domenech y Pérez Leirós. El primero estaba al frente de la CGT n ${ }^{\circ} 1$, en tanto que el segundo capitaneaba la $\mathrm{CGT}^{\circ}$ 2. Allí Herrera conjuga un detenido análisis de la situación gremial en dicha coyuntura y un abordaje centrado en el (re)posicionamiento del PS respecto de las centrales: las simpatías de la dirección partidaria no eran homogéneas, y al inicio parecían estar más cerca de la CGT n ${ }^{\circ} 1$ (que "metabolizaba" mejor la línea de la prescindencia). No obstante, con el correr del tiempo las simpatías inclinaron la balanza hacia la CGT $\mathrm{n}^{\circ} 2$, al menos si se tiene en cuenta la presencia rutilante de Pérez Leirós en las páginas de La Vanguardia en una fecha clave como el $1^{\circ}$ de mayo. Desde luego, su relación histórica con el PS, como bien advierte Herrera, no es un aspecto menor en este sentido.

En el tercer capítulo el foco se coloca en la "crisis externa", originada por el golpe de Estado de 1943, que llevó a las dos centrales obreras a pronunciarse públicamente y a mostrar interés por las acciones futuras de las nuevas autoridades. Estas expectativas se apagaron cuando la represión comenzó y el gobierno de facto restringió las actividades sindicales. En ese marco, incluso se clausuró el local de la CGT $n^{\circ} 2$, acto que fue muy cuestionado por La Vanguardia. De modo que, cuando Juan Domingo Perón comenzaba su diálogo con los sindicatos y convertía el antiguo Departamento Nacional de Trabajo en Secretaría de Trabajo y Previsión (STyP), el gremialismo socialista presentaba claros signos de debilidad. La UF se destacó (aunque 
no en soledad) en ese acercamiento, y no fueron pocos los socialistas que apoyaron la colaboración con las autoridades. En este acercamiento tuvo un papel clave el militante socialista Juan Atilio Bramuglia, que en poco tiempo se convirtió en Director de Asistencia Social de la STyP. A ello se le sumó la disolución de la CGT n ${ }^{\circ} 2$ y la reorganización de la CGT, que se consolidó y logró exponer sus planteos al gobierno. Finalmente, se revisa también cómo el accionar oficial desencadenó tensiones aún en ciertos dirigentes de la UF y el modo en el que desde la CGT algunos socialistas criticaban la intromisión de la STyP. No obstante, lejos estaba de ser uniforme la resistencia socialista: por ejemplo, Pérez Leirós y Borlenghi marcaron distancia inicialmente con respecto al apoyo a la STyP, pero posteriormente el segundo de ellos se pasó a las filas del "colaboracionismo" y el secretario general de Empleados de Comercio no sería el único.

Eso último desencadenó acciones entre los gremialistas socialistas que denotan diversas estrategias, y son reconstruidas con detalle en el cuarto capítulo. En este último, observa una fecha precisa en el que estos experimentaron un "corte definitivo" (12/07/1945). A partir de entonces, una vez desarrollado el acto público en el que Perón fue catalogado como "el gran conductor argentino del futuro" y hablaron varios dirigentes gremiales socialistas, era elocuente que muchos habían asumido una posición: el más saliente era Borlenghi, por eso Pérez Leirós lo identificaba como el coordinador del "entreguismo", pero también estaban Luis Monzalvo, Juan Ugazio, Pedro Otero, José Marotta y Manuel Pichel, para mencionar algunos. Este sector, que por cierto integró la nueva Comisión Administrativa provisoria de la CGT, comenzó a ser catalogado como los "traidores". Sin embargo, desde el PS no se entendía el colaboracionismo sin tener en cuenta el rol de las instancias estatales, a la vez que, al promediar 1945, consideraban que estaba en declive, razón por la cual había que defender la independencia del movimiento sindical. En una apuesta interesante, el autor del libro apela al análisis de casos para explicar que las estrategias elegidas por los actores no se comprenden en su complejidad sin tener en cuenta la estructura y la situación de los sindicatos. Así, la cuestión generacional no es más que un elemento integrado en una multiplicidad de factores, como se demuestra a través del estudio de los trabajadores municipales y los obreros del calzado.

El quinto capítulo se concentra en la resistencia de los socialistas, en la que tuvieron relevancia los sindicatos que no habían sido intervenidos, que adquirió mayor vigor aún desde comienzos de 1945. Así, plantea y caracteriza las "dos caras" de dicha resistencia: por un lado, la aparición del periódico Democracia Sindical, dirigido por Pérez Leirós, que se erigiría como la "voz auténtica del gremialismo libre"; por otro lado, la lucha por la recuperación de los sindicatos, que incluía el accionar de los socialista dentro de los gremios, la creación en gremios fuertes de sindicatos paralelos, el distanciamiento implícito de La Vanguardia respecto de la prescindencia, e incluso la activación de la Comisión Socialista de Coordinación Gremial en agosto de 1945, a través de la que se pretendía fortalecer la capacidad política de los militantes gremiales. El capítulo se cierra con el análisis socialista sobre "la primera sorpresa" (los días 17 y 18/10/1945), a partir de la evidencia obtenida especialmente en La Vanguardia y Democracia Sindical, y las iniciativas tendientes a lograr la unidad obrera a través de una nueva central que fuera independiente de las instancias estatales. Los albores de 1946 encontraban a los socialistas en esta tarea, a la vez que el Partido Laborista y los gremios en los que eran minoría se convertían en el principal blanco de ataques.

El sexto y último capítulo trata sobre el accionar del PS en el contexto preelectoral de 1946, e incluye una pesquisa que atiende a la aparición de Orientación Sindical, medio de prensa cuyo discurso reforzaba la idea de una nueva central obrera que garantizara la libertad, así como también lo que podríamos denominar "segunda sorpresa" (la derrota electoral de la Unión Democrática), que a pesar de todo no eliminó la postura opositora del socialismo. Al contrario, la actividad para llevar el socialismo a los gremios tuvo continuidad y, en esa coyuntura, ocurrió "un vuelco importante en la doctrina gremial oficial del PS". La activa tarea de la Comisión Nacional de Coordinación Gremial, y el planteo de La Vanguardia en torno a la "inoperante prescindencia gremial”, muestran a las claras para Herrera un cambio sustancial. El diluvio había barrido con uno de los pilares fundamentales del gremialismo socialista: en el XXXV Congreso del PS, que se realizó en julio de 1946, se resolvió derogar la prescindencia política en los gremios. A partir de ese momento, los 
gremialistas del PS no debían dejar sus ideas en la puerta del sindicato. Las dificultades, como bien se analiza al final de la obra, persistirían: no se alcanzó la unidad del movimiento obrero, como pretendían desde hace tiempo los socialistas, y el proyecto de crear otra central obrera se fue desvaneciendo. A mediados de 1947 el panorama era desolador, pero no claudicaron en el intento por defender la libertad sindical y crearon, en marzo de ese año, el Comité Obrero de Acción Sindical Independiente, que operó como "organismo de enlace" para hacer viable la convivencia de todas las organizaciones obreras "libres" del país. Este Comité, continuó activo hasta la década siguiente, cuando luego de la huelga ferroviaria de 1951 concluyó un ciclo de lucha y sus principales referentes debieron exiliarse.

El libro se cierra con un sugerente epílogo, en el que destaca dos sutiles planteos: en primer lugar, la tensión generada en el gremialismo socialista durante el paso de la politización del movimiento obrero a la estatalización de la actividad sindical y, en segundo lugar, la diferenciación que introduce para sopesar el accionar de los dirigentes gremiales durante el período en estudio, a partir de la cual ajusta cuentas con la clásica categoría de "vieja guardia sindical". Podríamos decir, junto con Pierre Vilar, que en muchos sentidos la historia es trágica... y tal vez el diluvio tuviera mucho de eso para los integrantes de esta cultura política. No obstante, agrega el historiador marxista, "es mejor dedicar nuestros esfuerzos a comprenderla que a intentar salir de ella" (Vilar, 2004, p. 168). Sin duda, este nuevo libro de Herrera le hace honores a dicho planteo y logra, con la mirada atenta siempre en los actores concretos, un sólido acercamiento a un tema que ahora, mediante esta obra, podemos conocer mucho mejor.

\section{ReFERENCIAS}

Vilar, P. (2004). Pensar históricamente. Barcelona: Crítica. 